\title{
Adsorption and surface diffusion of silicon growth species in silicon carbide chemical vapour deposition processes studied by quantum-chemical computations
}

\author{
Emil Kalered, Henrik Pedersen, Erik Janzén and Lars Ojamäe
}

\section{Linköping University Post Print}

\section{Tweet}

N.B.: When citing this work, cite the original article.

The original publication is available at www.springerlink.com:

Emil Kalered, Henrik Pedersen, Erik Janzén and Lars Ojamäe, Adsorption and surface diffusion of silicon growth species in silicon carbide chemical vapour deposition processes studied by quantum-chemical computations, 2013, Theoretical Chemistry accounts, (132), 12. http://dx.doi.org/10.1007/s00214-013-1403-3

Copyright: Springer Verlag (Germany)

http://www.springerlink.com/?MUD=MP

Postprint available at: Linköping University Electronic Press

http://urn.kb.se/resolve?urn=urn:nbn:se:liu:diva-100478 


\title{
Adsorption and surface diffusion of silicon growth species in silicon carbide chemical vapour deposition processes studied by quantum chemical computations
}

\author{
Emil Kalered, Henrik Pedersen, Erik Janzén, Lars Ojamäe \\ Department of Physics, Chemistry and Biology, Linköping University, SE-581 83 Linköping, Sweden
}

The effect chlorine addition to the gas mixture has on the surface chemistry in the chemical vapour deposition process for silicon carbide ( $\mathrm{SiC}$ ) epitaxial layers is studied by quantum-chemical calculations of the adsorption and diffusion of $\mathrm{SiH}_{2}$ and $\mathrm{SiCl}_{2}$ on the (000-1) $4 \mathrm{H}-\mathrm{SiC}$ surface. $\mathrm{SiH}_{2}$ was found to bind stronger to the surface than $\mathrm{SiCl}_{2}$ by approximately $100 \mathrm{~kJ} \mathrm{~mol}^{-1}$ and to have a $50 \mathrm{~kJ} \mathrm{~mol}^{-1}$ lower energy barrier for diffusion on the fully hydrogen-terminated surface. On a bare $\mathrm{SiC}$ surface, without hydrogen termination, the $\mathrm{SiCl}_{2}$ molecule has a somewhat lower energy barrier for diffusion. $\mathrm{SiCl}_{2}$ is found to require a higher activation energy for desorption once chemisorbed, compared to the $\mathrm{SiH}_{2}$ molecule. Gibbs free-energy calculations also indicate that the $\mathrm{SiC}$ surface may not be fully hydrogen terminated at CVD conditions since missing-neighbouring pair of surface hydrogens is found to be a likely type of defect on a hydrogen terminated SiC surface.

\section{Introduction}

During the last twenty years, the interest in silicon carbide ( $\mathrm{SiC}$ ) based electric devices has greatly increased due to the superior properties, e.g. higher operation temperature, higher thermal conductivity and higher critical electrical breakdown field [1, 2], compared to conventional silicon based devices. A critical factor holding back the development of silicon carbide technology is the significantly higher manufacturing costs compared to conventional semiconductor materials and especially compared to silicon. A substantial part of the production cost of the final device is the cost for manufacturing the active region. This region is usually manufactured as an epitaxial layer, grown with great precision, in terms of crystal quality and impurity levels, on top of a single crystalline substrate. For a long time, the method of choice for epitaxial growth of silicon carbide has been Chemical Vapour Deposition (CVD). The silicon and carbon precursors typically used in SiC CVD are high purity silane, $\mathrm{SiH}_{4}$, and small hydrocarbon molecules, e.g. ethylene, $\mathrm{C}_{2} \mathrm{H}_{4}$, or propane, $\mathrm{C}_{3} \mathrm{H}_{8}$. These gases are diluted approximately one thousand times in a $\mathrm{H}_{2}$ carrier gas flow that is used as solvent and is also needed for the growth chemistry. The process temperature and pressure is usually $1500-1600{ }^{\circ} \mathrm{C}$ and $100-1000 \mathrm{mBar}$, 
respectively. Typically, SiC CVD processes operate with a growth rate of 5-10 $\mu \mathrm{m} / \mathrm{h}[3]$, to be compared to a few hundred of $\mu \mathrm{m} / \mathrm{h}$ for epitaxial growth of silicon [4].

To increase the growth rate of epitaxial layers of $\mathrm{SiC}$, the number of silicon and carbon atoms interacting with the substrate per time unit must be increased. This is achieved by increasing the concentration of silicon and carbon in the gas mixture. However the drawback of increased gas phase concentrations is the increased probability of formation of solid aggregates in the gas phase, mainly silicon droplets, which in contact with the surface causes severe crystal defects making the epitaxial layer unusable for electric devices.

In order to avoid the formation of silicon droplets, an element can be added to the gas mixture that binds stronger to silicon than silicon itself. Good candidates for this are the halogens, where the standard bond enthalpies for the Si-Si, Si-F, Si-Cl, Si-Br and Si-I bonds are 226, 597, 400, 330 and $234 \mathrm{~kJ} \mathrm{~mol}^{-1}$ respectively [5]. Of these, the bromine and iodine atoms are rather large and, especially iodine forms a too weak bond to silicon. The fluorine on the other hand, binds too strongly to silicon and can also form very toxic HF gas in reactions with the hydrogen carrier gas. So the $\mathrm{Si}-\mathrm{Cl}$ bond turns out to be the one with the best suited bond enthalpy. A further advantage with using chlorine as growth additive is that chlorinated silicon compounds are available in high purity since they are already commercially used in the silicon industry. The CVD process where chloride is added to the gas mixture is often called chloride-based CVD and it has been shown to be a route to achieve growth rates $>100 \mu \mathrm{m} / \mathrm{h}$ at otherwise standard process conditions, but it has also opened up for low temperature $\left(1300^{\circ} \mathrm{C}\right)$ processes with growth rates around 5-10 $\mu \mathrm{m} / \mathrm{h}[6]$.

Chloride was mainly introduced in SiC CVD to circumvent the formation of the silicon droplets, however, the introduction also means that the chemistry, both the gas phase chemistry and the surface chemistry, in the process changes. According to thermophysical studies of the gas-phase chemistry, the actual molecules interacting with the surface are mainly $\mathrm{SiCl}_{2}$ in chloride-based CVD [7-9] as compared to mainly $\mathrm{SiH}_{2}$ in conventional CVD [7, 9]. For a better understanding of the impact of the chloride-based chemistry on the growth, the differences in how the $\mathrm{SiCl}_{2}$ and $\mathrm{SiH}_{2}$ molecules interact with the $\mathrm{SiC}$ surface are of great interest. Here we probe the surface chemistry of $\mathrm{SiCl}_{2}$ and $\mathrm{SiH}_{2}$ to study differences crucial to their behaviour in a CVD process.

Quantum-chemical calculations have previously been used to study the surface chemistry in silicon carbide CVD [10-13]. Larsson et al. [10] have studied adsorption and abstraction of hydrogen on hydrogen-terminated (0001) and (000-1) surfaces on $4 \mathrm{H}-\mathrm{SiC}$ and found that the two hydrogen-terminated surfaces are stable enough to 
endure temperatures up to $2300^{\circ} \mathrm{C}$ even in presence of hydrogen or halogen radicals [10]. Reconstruction of the unterminated (0001) and (000-1) surfaces upon adsorption was investigated [11] and it was found that the (0001) surface obtained a $(1 \times 2)$ reconstruction whereas the $(000-1)$ surface retained its initial $(1 \times 1)$ structure. Both surfaces gained parameters closer to the bulk parameters when species, i.e. $\mathrm{C}_{2} \mathrm{H}_{2}$ and $\mathrm{Si}$, were adsorbed on the surface [11]. A study by Wachowicz and Kiejna [12] shows that hydrogen-termination of a naked 4H-SiC cluster suppresses the surface relaxation.

In this work hybrid ab initio - DFT calculations was performed using a cluster model to investigate adsorption and diffusion of $\mathrm{SiH}_{2}$ and $\mathrm{SiCl}_{2}$ on the (000-1) $4 \mathrm{H}-\mathrm{SiC}$ surface. Both fully hydrogen-terminated surfaces and surfaces with hydrogen vacancy sites were studied with the purpose to investigate the difference in growth behaviour in the CVD process using standard and chlorinated growth chemistry.

\section{Method}

The interaction between the hydrogen-terminated $4 \mathrm{H}-\mathrm{SiC}(000-1)$ surface, also denoted as the carbon face, or $\mathrm{C}$ face of a $\mathrm{SiC}$ wafer, and the two molecules $\mathrm{SiH}_{2}$ and $\mathrm{SiCl}_{2}$ were investigated using quantum-chemical calculations. The surface was modelled using a cluster of atoms, cut from the bulk crystal structure. $4 \mathrm{H}-\mathrm{SiC}$ crystallize in a hexagonal structure with space group $\mathrm{P}_{3} \mathrm{mc}$ and the lattice parameters $\mathrm{a}=3.08 \AA$ and $\mathrm{c}=10.08$ $\AA$ [13]. The clusters were cut in such a way that the number of unsaturated bonds was minimized and the atom coordination was maximized. Clusters with various sizes, ranging from 26 to 400 atoms, were constructed and their structures relaxed (i.e. geometry optimized) [14] to find the local energy-minima structures. The clusters were studied both with and without hydrogen saturating the dangling bonds at the surfaces.

The quantum-chemical calculations were mainly performed using the B3LYP hybrid ab initio-density functional theory method $[15,16]$ with a double zeta basis set (DZ) $[17,18]$ used for initial geometry-optimization calculations and the larger 6-31G(d,p) basis set [19] for final optimizations and for property calculations. In geometry-optimization calculations on the molecules occurring in this study, the additional ab initio electron correlation-corrected methods MP2 [20] and QCISD(T) [21] were also used, as well as the large basis set 6$311++\mathrm{G}(2 \mathrm{df}, 2 \mathrm{pd})$ [22]. The quantum-chemical program Gaussian 09 [23] was employed. The use of a cluster model facilitates the application of hybrid ab initio - DFT calculations.

When calculating the Gibbs free energy via a vibrational normal mode computation in the Gaussian 09 program, a temperature of $1870 \mathrm{~K}$ and partial pressures according to table 1 were used. The temperature and pressure used are based on common parameters in CVD processes of silicon carbide [6]. 
Transition-state energies and structures were obtained using the Synchronous Transit-Guided Quasi-Newton (STQN) method $[24,25]$ in the Gaussian 09 program, which uses a quadratic synchronous transit (QST) approach [26] followed by a quasi-Newton algorithm.

Table 1. The partial pressure used in the calculations of thermodynamical properties.

\begin{tabular}{ll}
\hline Molecule & Pressure [atmospheres] \\
\hline $\mathrm{H}_{2}$ & 0.1 \\
$\mathrm{SiCl}_{2}$ & 0.0004 \\
$\mathrm{SiH}_{2}$ & 0.0004 \\
$\mathrm{HCl}$ & 0.0016 \\
\hline
\end{tabular}

The influence from spin multiplicity on the molecular energies was investigated for the two molecules $\mathrm{SiH}_{2}$ and $\mathrm{SiCl}_{2}$, see table 2 . As can been seen, the energy for the singlet state is lower than the energy for the triplet state for both $\mathrm{SiH}_{2}$ and $\mathrm{SiCl}_{2}$. Henceforth the singlet state is used as default state for these molecules. Similar result for the $\mathrm{SiCl}_{2}$ molecule was reported in [27]. From table 2 it is seen that the agreement is good between the B3LYP/6 31G(d,p) results and the results using MP2 or CCSD(T) together with a large basis set.

Table 2. Bond length, angles and energy difference between singlet and triplet states for $\mathrm{SiH}_{2}$ and $\mathrm{SiCl}_{2}$ using different methods and basis set. $\mathrm{X}$ denotes $\mathrm{Cl}$ and $\mathrm{H}$ respectively. $\mathrm{E}_{\mathrm{t}}-\mathrm{E}_{\mathrm{s}}$ is the difference between the triplet state and singlet state energies.

\begin{tabular}{|c|c|c|c|c|c|c|}
\hline \multirow[t]{2}{*}{ Structure } & \multirow[t]{2}{*}{ Method } & \multicolumn{2}{|c|}{$\mathbf{S i}-\mathbf{X}[\AA]$} & \multicolumn{2}{|c|}{$\mathrm{XSiX}$ angle $\left[{ }^{\circ}\right]$} & \multirow{2}{*}{$\begin{array}{l}\mathbf{E}_{\mathrm{t}}-\mathbf{E}_{\mathrm{s}} \\
{\left[\mathrm{kJ} \mathrm{mol}^{-1}\right]}\end{array}$} \\
\hline & & Singlet & Triplet & Singlet & Triplet & \\
\hline \multirow[t]{5}{*}{$\mathrm{SiH}_{2}$} & B3LYP/DZ & 1.56 & 1.50 & 91.2 & 118.7 & 73 \\
\hline & B3LYP/6-31G(d,p) & 1.53 & 1.49 & 91.3 & 118.4 & 83 \\
\hline & B3LYP/6 311++G(2df,2pd) & 1.52 & 1.49 & 91.6 & 118.6 & 86 \\
\hline & MP2/6-311++G(2df,2pd) & 1.51 & 1.47 & 92.2 & 118.2 & 67 \\
\hline & $\mathrm{QCISD}(\mathrm{T}) / 6-311++\mathrm{G}(2 \mathrm{df}, 2 \mathrm{pd})$ & 1.52 & 1.48 & 92.3 & 118.3 & 83 \\
\hline \multirow[t]{5}{*}{$\mathrm{SiCl}_{2}$} & B3LYP/DZ & 2.24 & 2.22 & 101.8 & 120.4 & 221 \\
\hline & B3LYP/6-31G(d,p) & 2.11 & 2.08 & 102.3 & 119.1 & 222 \\
\hline & B3LYP/6 311++G(2df,2pd) & 2.10 & 2.07 & 101.8 & 118.6 & 223 \\
\hline & MP2/6-311++G(2df,2pd) & 2.08 & 2.05 & 101.3 & 118.6 & 213 \\
\hline & $\operatorname{QCISD}(\mathrm{T}) / 6-311++\mathrm{G}(2 \mathrm{df}, 2 \mathrm{pd})$ & 2.09 & 2.06 & 101.6 & 117.6 & 221 \\
\hline
\end{tabular}




\section{Results and Discussion}

\section{1 $\mathrm{SiC}$ clusters}

\subsubsection{Structures and cohesive energies}

For hydrogen-terminated clusters (Fig. 1), the silicon-carbon bond lengths were found to be $1.915 \pm 0.01 \AA$ in the bulk and $1.895 \pm 0.01 \AA$ at the surface after geometry optimization. The angles between silicon-carbon bonds were $109.4^{\circ} \pm 0.2^{\circ}$ for bonds inside the cluster and somewhat larger $\left(110.5^{\circ} \pm 0.5^{\circ}\right)$ for angles between siliconcarbon bonds at the surface. Thus the bond lengths and angles of the clusters are close to the initial bond-lengths of $1.89 \AA$ and the bond angles of $109.5^{\circ}$ calculated from the experimental lattice parameters. 


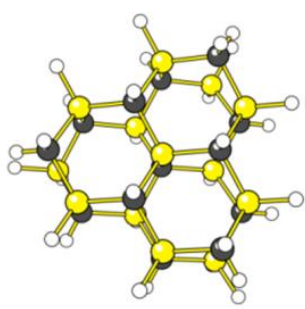

a

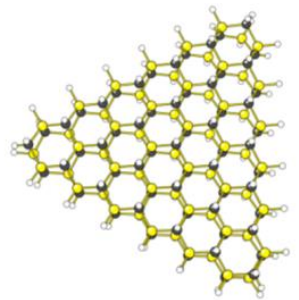

e
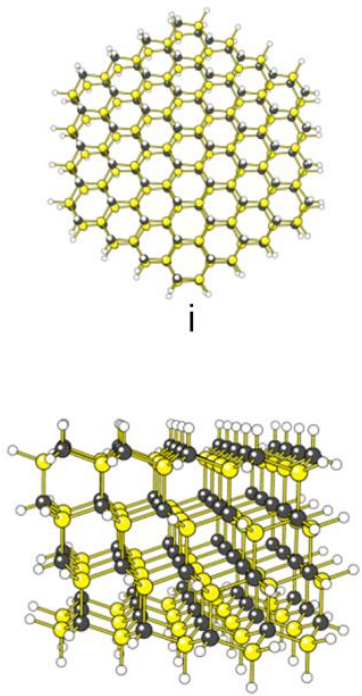

m

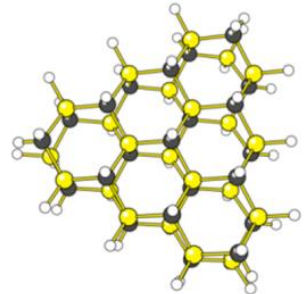

b

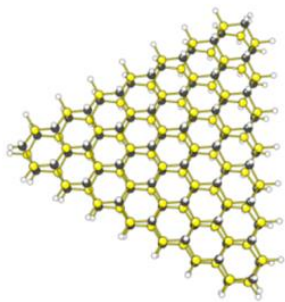

f
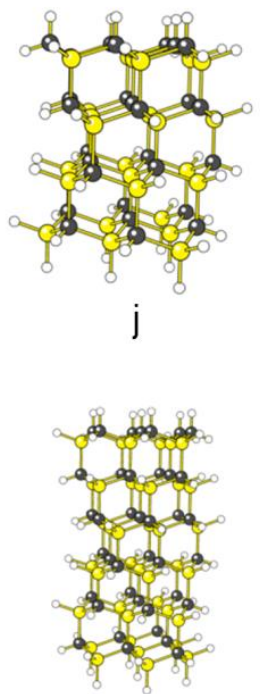

n

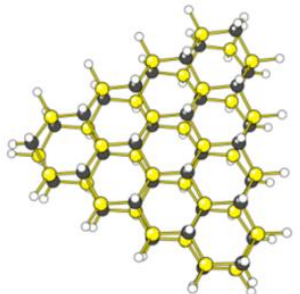

C

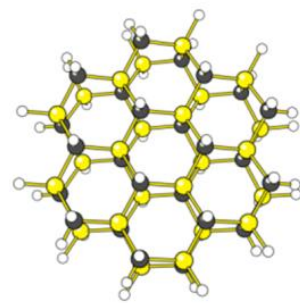

g

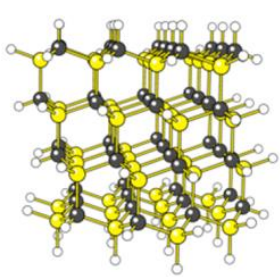

k

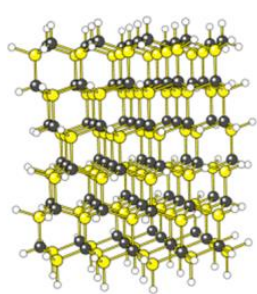

0

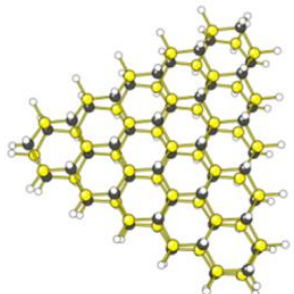

d

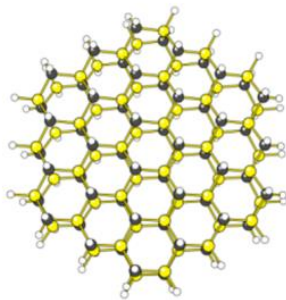

h
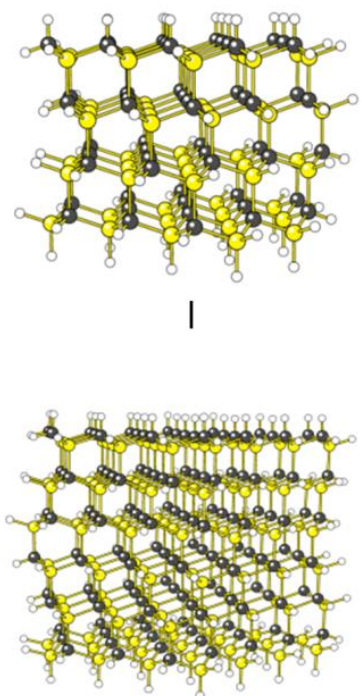

$p$

Fig. 1 The different hydrogen-terminated clusters used, a-f: two layer triangular shape, g-i: two layer round shape, j-m: four layer triangular shape, n-p: six layer triangular shape. The cluster pictures were drawn using Moviemol [28].

If the clusters in Fig. 1 were geometry-optimized without the hydrogen termination the structures were significantly deformed. The silicon-carbon bond lengths varied to a large extent, i.e. 1.80-1.96 A. More important, the angles between silicon-carbon bonds deviated from the crystal angle of $109.5^{\circ}$ by up to $5^{\circ}$ inside the clusters and up to $30^{\circ}$ between bonds at the surface. The two-layer clusters obtained cage-like structures and the silicon-carbon bond length decreased to an average of $1.83 \AA$. An example of this is shown in Fig. 2 for the cluster from Fig. 1b stripped of its hydrogens. The same behaviour has been observed in GaN clusters [29]. The large surface relaxation in clusters covered with dangling bonds makes them less suitable as models for the 
crystal surface when studying the adsorption processes; in the present study the H-terminated clusters (in some cases with one or two $\mathrm{H}$ vacancies) were used.

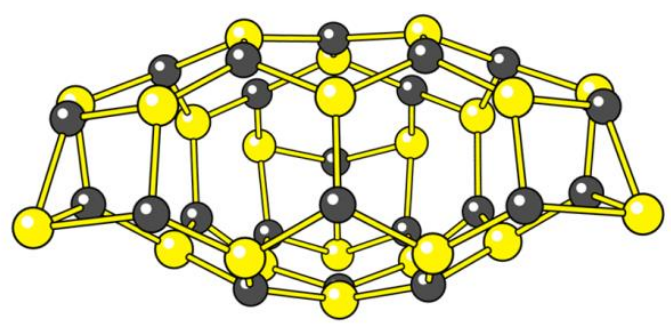

Fig. 2 The $\mathrm{Si}_{22} \mathrm{C}_{22}$ structure, a two-layer cluster without hydrogen termination after the geometry was relaxed.

Due to the large amount of dangling bonds in a cluster without hydrogen termination its favoured spin state is not obvious. The effect of spin multiplicity on the cluster energy was investigated for one cluster without hydrogen termination (Fig 2). Geometry optimizations using different spin states showed that the singlet state was lower in energy than the triplet state by $49 \mathrm{~kJ} \mathrm{~mol}^{-1}$, and the energy increased for higher spin multiplicities.

The cohesive energies per $\mathrm{SiC}$ unit for the hydrogen-terminated clusters were calculated using two different methods. The first method uses the following formula to calculate the cohesive energy per SiC unit:

$$
\Delta E_{c o h}=\frac{E_{t o t}-n\left(E_{S i}+E_{C}\right)-m \frac{E_{H_{2}}}{2}}{n}
$$

$E_{\text {tot }}$ is the total potential energy of the geometry-optimized hydrogen-terminated SiC cluster, obtained from the quantum-chemical calculation (i.e. the sum of the electron-electron, nuclei-nuclei and electron-nuclei potential energies plus the electron kinetic energies). $n$ is the number of $\mathrm{SiC}$ units, $E_{S i}$ is the energy for a free silicon atom, $E_{C}$ is the energy for a free carbon atom, $m$ is the number of hydrogen atoms. $E_{\mathrm{H}_{2}}$ is the energy for a hydrogen molecule.

In the second method, the energy contributions from the hydrogen atoms at the surface were subtracted. The idea was to thereby remove the surface energy from the cohesive energies. The following formula was used:

$$
\Delta E_{c o h}=\frac{E_{t o t}-n\left(E_{S i}+E_{C}\right)-m E_{H, s u r f}}{n}
$$

$E_{t o t}$ is the total electronic energy (i.e. the potential energy of the nuclei) for the hydrogen-terminated $\mathrm{SiC}$ cluster as before. $m$ is the number of hydrogen atoms. $E_{H, \text { surf }}$ is estimated from the energy difference between a fully 
hydrogen terminated cluster and a cluster with one hydrogen atom removed, averaged over different hydrogen atoms.

The cohesive energy variation with respect to size of the cluster is displayed in Fig. 3. Presuming that the cluster energy depends approximately linearly on both surface area and on the volume the relationship between total energy per $\mathrm{SiC}$ unit and number of $\mathrm{SiC}$ units can be derived.

$$
\frac{E_{t o t}}{n}=a \cdot n^{-1 / 3}+b
$$

where $a$ and $b$ are constants and $n$ is the number of $\mathrm{SiC}$ units. Thus the trend will be that the cohesive energy per $\mathrm{SiC}$ unit $\left(\Delta \mathrm{E}_{\mathrm{coh}}\right)$ will depend approximately linearly on the number of units raised to the power of minus one third $\left(n^{-1 / 3}\right)$.

In Fig. 3, both methods for estimating the cohesive energy are shown using a subset of clusters that increase in size simultaneously in three dimensions, see fig 1 a-c. As Fig. 3 shows, both methods extrapolate to the same value of the cohesive energy per $\mathrm{SiC}$ unit, $\sim 1700 \mathrm{~kJ} \mathrm{~mol}^{-1}$, when the cluster size approaches infinity. That the two formulas extrapolate to the same value is to be expected since the surface effects are negligible for very large clusters.

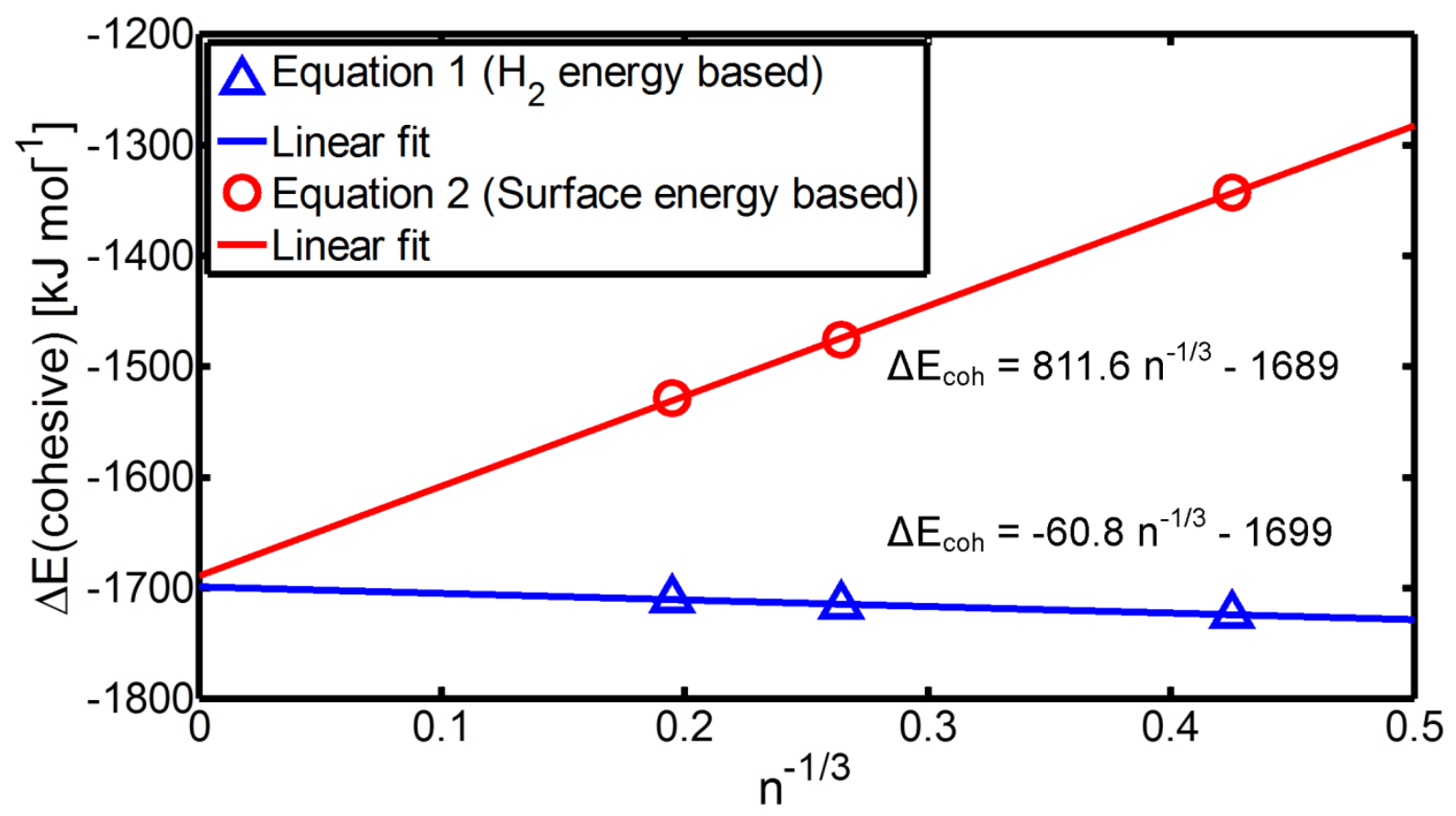

Fig. 3 Cohesive energy per $\mathrm{SiC}$ unit versus number of $\mathrm{SiC}$ units raised to minus one third. The two different methods used are described in the text, equation (1) and (2). The clusters used are shown in Figs. 1a, 11 and 1p. 


\subsubsection{Band gap}

The band-gap energies for the clusters were estimated from the energy differences between the highest occupied and lowest unoccupied molecular orbitals (HOMOs and LUMOs), see Fig. 4. The band gap is relatively large for the small clusters which can be attributed to the quantum confinement effect [30] and decreases with increasing cluster size. In Fig. 5, band gap energies for a subset of clusters, chosen to increase simultaneously in size in all three dimensions, are plotted. The extrapolated value of the band gap as the cluster size grows toward infinity is $4.17 \mathrm{eV}$, which may be a rather crude estimation since only three data points were used in the extrapolation. For comparison the experimental value for the band gap in $4 \mathrm{H}-\mathrm{SiC}$ is $3.2 \mathrm{eV}[31]$.

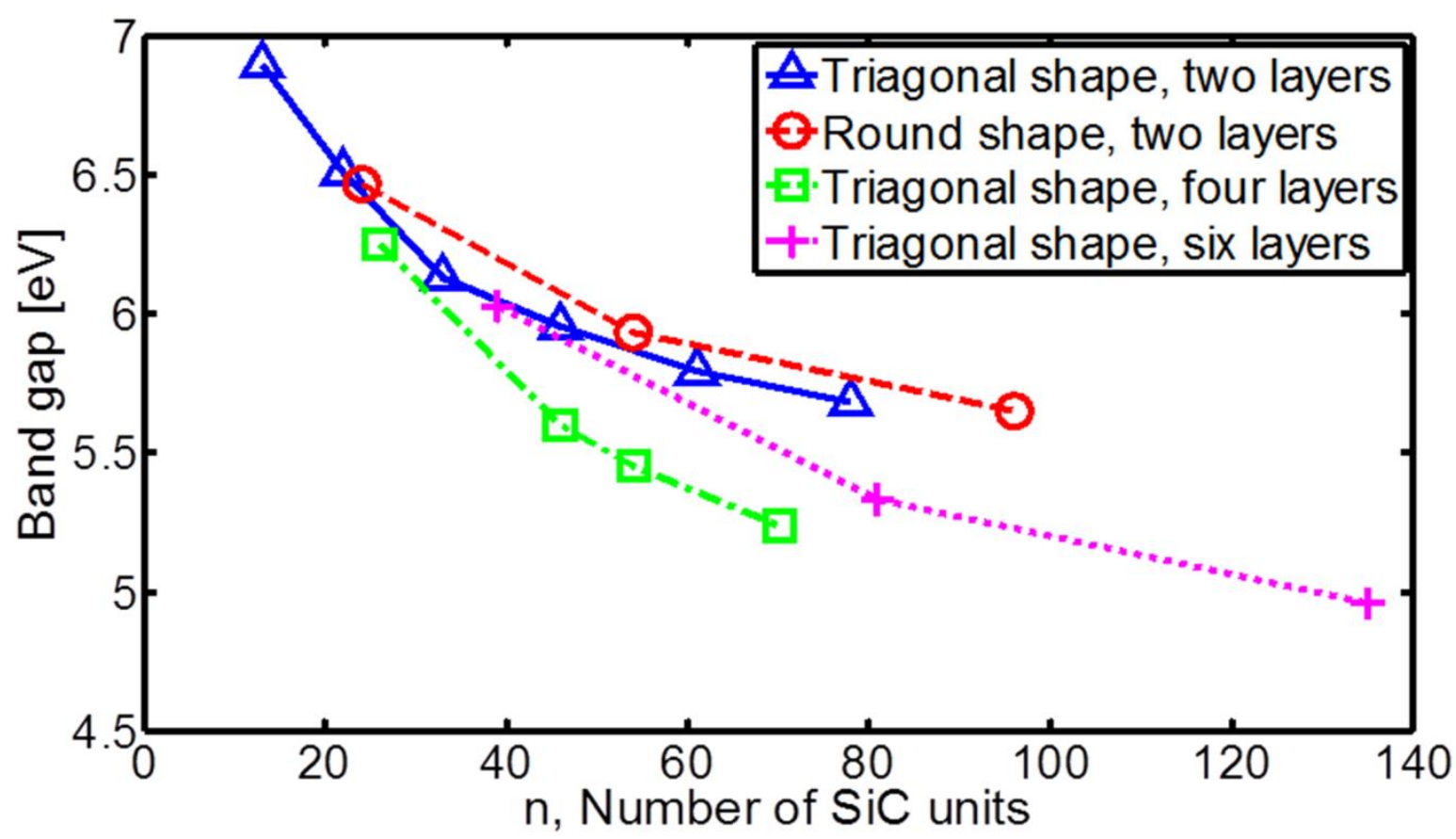

Fig. 4 Band gap energies plotted versus cluster size. The B3LYP functional and the basis set 6-31G(d,p) were used. The cluster structures are displayed in Fig. 1. 


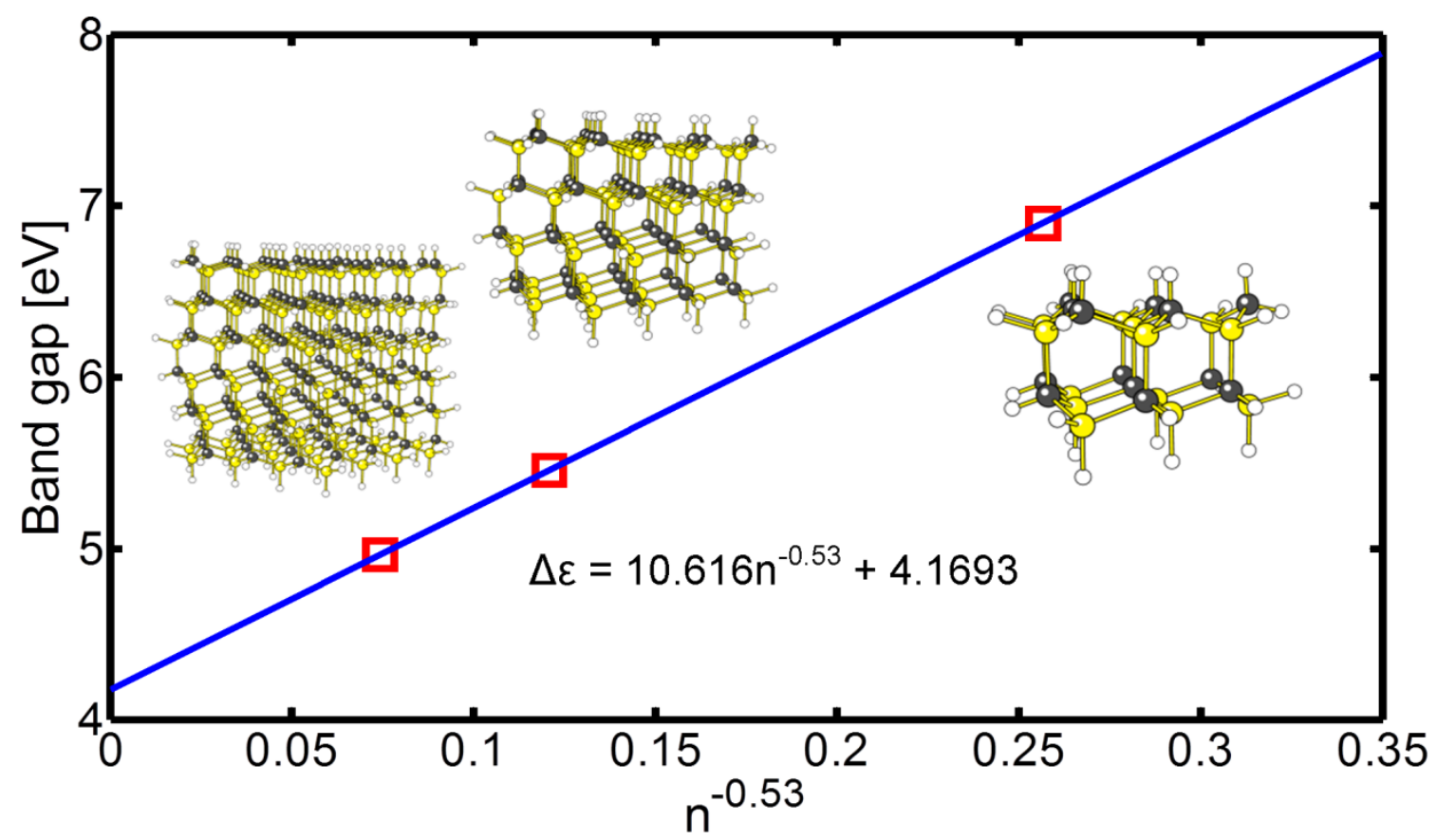

Fig. 5 Band gap versus number of $\mathrm{SiC}$ units to the power of -0.53 for a set of clusters whose sizes were uniformly increased in three dimensions, see Figs. 1a, 11 and 1p.

\subsection{Surface Reactions}

Reactions for $\mathrm{SiH}_{2}$ and $\mathrm{SiCl}_{2}$ at the $\mathrm{SiC}$ surface were studied. Also the reaction energy for removal of hydrogen from the surface was investigated. The cluster used to model the SiC (000-1) surface was the hydrogen-saturated triangular shaped $\mathrm{H}_{60} \mathrm{Si}_{33} \mathrm{C}_{33}$ cluster shown in Fig. 1c.

\subsubsection{Subtraction of surface hydrogen}

An initial study was carried out of the energetics of subtraction of hydrogen from the surface of the hydrogenterminated SiC cluster:

$$
H(a d s) \rightarrow \frac{1}{2} H_{2}(g)
$$

The reaction energy $\Delta \mathrm{E}$ for the removal of one surface hydrogen was found to be $198 \mathrm{~kJ} \mathrm{~mol}^{-1}$. Removal of a second, adjacent, hydrogen corresponded to the reaction energy $309 \mathrm{~kJ} \mathrm{~mol}^{-1}$. (If instead the product is the radical $\mathrm{H}(\mathrm{g})$ rather than the molecular hydrogen, the reaction energy for removal of the first hydrogen is $432 \mathrm{~kJ}$ $\mathrm{mol}^{-1}$ and for the second $543 \mathrm{~kJ} \mathrm{~mol}^{-1}$. These can be compared to the internal energy reaction energies 367 and $587 \mathrm{~kJ} \mathrm{~mol}^{-1}$ obtained in Ref. [10].)

The reaction Gibbs free energies for removal of one surface hydrogen to form molecular hydrogen was found to be $40 \mathrm{~kJ} \mathrm{~mol}^{-1}$ at the $\mathrm{H}_{2}$ pressure in table 1. Interestingly, for removal of the second hydrogen the free energy 
difference is $-40 \mathrm{~kJ} \mathrm{~mol}^{-1}$, which means that Gibbs free energy difference when two neighbouring hydrogen are removed is about $0 \mathrm{~kJ} \mathrm{~mol}^{-1}$. The reaction Gibbs free energy for removal of all hydrogen on the (000-1) surface of the cluster is about $42 \mathrm{~kJ} \mathrm{~mol}^{-1}$ per hydrogen atom, i.e. the bare surface is thermodynamically less stable than the hydrogenated surface in agreement with the result in Ref. [10]. But the close to zero reaction Gibbs free energy for the removal of a pair of hydrogen indicates that this kind of missing-neighbouring pair of hydrogens might be a not uncommon type of defect at CVD growth conditions.

\subsubsection{Adsorption of $\mathrm{SiH}_{2}$ and $\mathrm{SiCl}_{2}$}

Adsorption of $\mathrm{SiH}_{2}$ and $\mathrm{SiCl}_{2}$ was studied by allowing the molecules to replace one adsorbed hydrogen atom, see reaction 1 and 2 in table 3 and Fig. 6a, or allowing them to replace two adsorbed hydrogen atoms to form a Si bridge between two carbon atoms in the surface, see reaction 3 and 5 in table 3 and Fig. $6 \mathrm{~b}$. An alternative studied adsorption mechanism is to let two $\mathrm{SiH}_{2}$ or $\mathrm{SiCl}_{2}$ molecules replace two adsorbed hydrogen atoms, forming two Si-C bonds to two carbon atoms in the surface, see reaction 4 and 6 in table 3 and Fig. $6 \mathrm{c} . \mathrm{H}_{2}(\mathrm{~g})$ is formed as byproduct in the reactions above. Further, adsorption was also studied by letting a $\mathrm{SiH}_{2}$ or $\mathrm{SiCl}_{2}$ replace one adsorbed hydrogen atom, forming a $\mathrm{Si}-\mathrm{C}$ bond, and then transfer the hydrogen to the $\mathrm{Si}$ atom, forming an additional $\mathrm{Si}-\mathrm{H}$ bond, see reaction 7 and 8 in table 3.

Table 3. The adsorption reaction energies for various adsorption types for $\mathrm{SiH}_{2}$ and $\mathrm{SiCl}_{2}$ on the model $\mathrm{SiC}$ (000-1) surface in Fig. 1c. The Gibbs free energy was calculated using a temperature of $1870 \mathrm{~K}$ and pressures according to table 1 . The functional B3LYP together with the basis set $6-31 \mathrm{G}(\mathrm{d}, \mathrm{p})$ was used.

\section{Reaction}

\section{Adsorption reaction energy}

$$
\Delta \mathrm{E}\left[\mathrm{kJ} \mathrm{mol}^{-1}\right] \quad \Delta \mathrm{G}\left[\mathrm{kJ} \mathrm{mol}^{-1}\right]
$$

\begin{tabular}{llcl}
\hline 1. & $\mathrm{SiH}_{2}(\mathrm{~g})+\mathrm{H}(\mathrm{ads}) \rightarrow \mathrm{SiH}_{2}(\mathrm{ads})+1 / 2 \mathrm{H}_{2}(\mathrm{~g})$ & -57 & 199 \\
2. & $\mathrm{SiCl}_{2}(\mathrm{~g})+\mathrm{H}(\mathrm{ads}) \rightarrow \mathrm{SiCl}_{2}(\mathrm{ads})+1 / 2 \mathrm{H}_{2}(\mathrm{~g})$ & 27 & 305 \\
\hline 3. & $\mathrm{SiH}_{2}(\mathrm{~g})+2 \mathrm{H}(\mathrm{ads}) \rightarrow \mathrm{SiH}_{2}(\mathrm{ads})+\mathrm{H}_{2}(\mathrm{~g})$ & -14 & 219 \\
4. & $2 \mathrm{SiH}_{2}(\mathrm{~g})+2 \mathrm{H}(\mathrm{ads}) \rightarrow 2 \mathrm{SiH}_{2}(\mathrm{ads})+\mathrm{H}_{2}(\mathrm{~g})$ & -395 & 261 \\
5. & $\mathrm{SiCl}_{2}(\mathrm{~g})+2 \mathrm{H}(\mathrm{ads}) \rightarrow \mathrm{SiCl}_{2}(\mathrm{ads})+\mathrm{H}_{2}(\mathrm{~g})$ & 105 & 447 \\
6. & $2 \mathrm{SiCl}_{2}(\mathrm{~g})+2 \mathrm{H}(\mathrm{ads}) \rightarrow 2 \mathrm{SiCl}_{2}(\mathrm{ads})+\mathrm{H}_{2}(\mathrm{~g})$ & -184 & 206 \\
\hline 7. & $\mathrm{SiH}_{2}(\mathrm{~g})+\mathrm{H}(\mathrm{ads}) \rightarrow \mathrm{SiH}_{3}(\mathrm{ads})$ & -214 & 334 \\
8. & $\mathrm{SiCl}_{2}(\mathrm{~g})+\mathrm{H}(\mathrm{ads}) \rightarrow \mathrm{SiCl}_{2} \mathrm{H}(\mathrm{ads})$ & -123 & \\
\hline
\end{tabular}




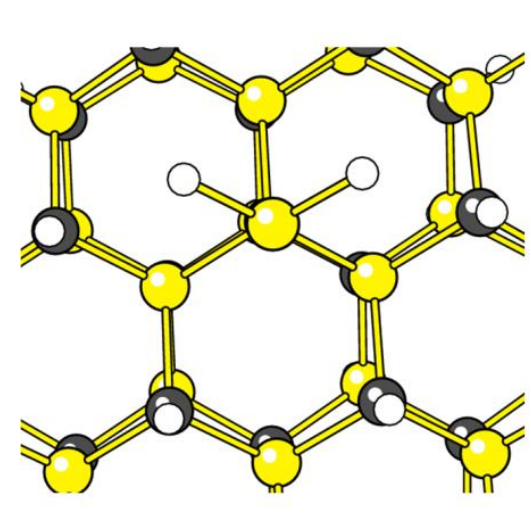

a (reaction 1)

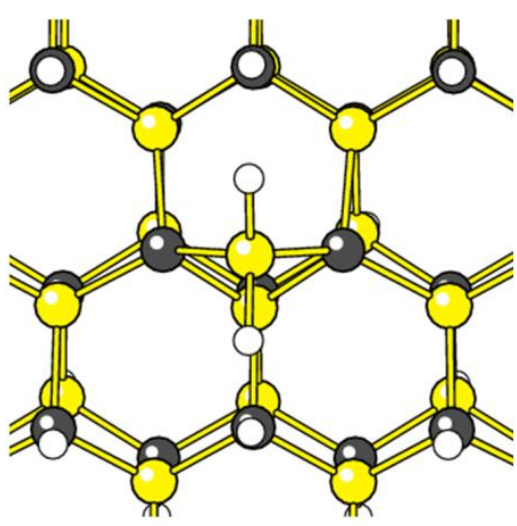

b (reaction 3)

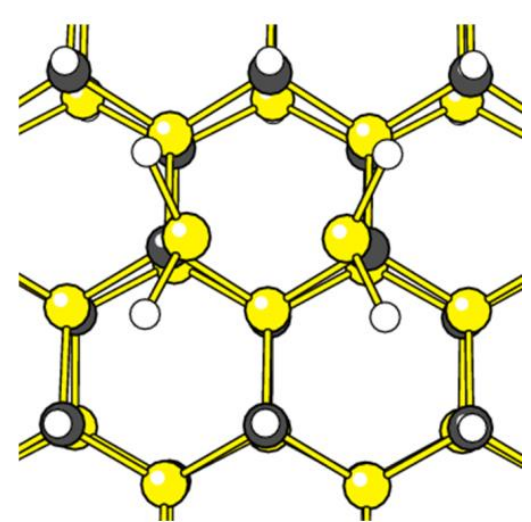

c (reaction 4)

Fig. 6 The adsorbed molecules in reaction 1, 3 and 4. The corresponding structures for $\mathrm{SiCl}_{2}$ are very similar and are therefore not shown.

The adsorption reaction energies were calculated according to the formula $\Delta \mathrm{E}_{\text {ads }}=\Sigma \mathrm{E}$ (products)- $\Sigma \mathrm{E}$ (reactants).

This definition of adsorption reaction energy gives a negative value for the adsorption energy when there is a decrease in total energy for the system, implying an exothermic process and an energetically favourable adsorption, or attraction. The adsorption reaction energies are shown in table 3.

In reaction 1 and 2, one molecule is adsorbed and one half hydrogen molecule is removed. The adsorption reaction energies $(\Delta \mathrm{E})$ are $-57 \mathrm{~kJ} \mathrm{~mol}^{-1}$ for $\mathrm{SiH}_{2}$ and $27 \mathrm{~kJ} \mathrm{~mol}^{-1}$ for $\mathrm{SiCl}_{2}$ and the position of the silicon atom of the molecule is close to that of a crystal lattice position. The silicon-carbon bond length $(1.89 \AA)$ to the adsorbed silicon is $0.02 \AA$ shorter than the mean value for silicon-carbon bond lengths for both $\mathrm{SiH}_{2}$ and $\mathrm{SiCl}_{2}$. The adsorbed silicon is negligible tilted for the $\mathrm{SiH}_{2}$ molecule and for the $\mathrm{SiCl}_{2}$ molecule roughly $6^{\circ}$ tilted compared to the geometry optimized crystal structure. There is a negligible deformation in the cluster and thereby insignificant strain.

The adsorption reaction energies are low for reaction 3 and even positive for reaction 5 . In reaction 3 and 5, the molecules are adsorbed by forming bonds to two adsorption sites and thereby saturating its dangling bonds, but the surface structure is deformed in the adsorption process, since the two adsorption sites are brought closer together, see Fig. 6 b. The deformation creates a strain in the cluster which increases its total energy.

In reactions 4 and 6, two molecules adsorbs at two adjacent sites. The adsorption energies indicate that these reactions are more favourable compared to reactions 3 and 5. Also, for this adsorption mode, the silicon positions at the surface are more similar to those in the crystal structure. In this structure the two silicon atoms in the adsorbed molecules have one unsaturated bond each which leads to an attraction between the two molecules, 
resulting in a silicon-silicon bond. Thereby the silicon atoms obtain standard $\mathrm{sp}^{3}$ hybridizations, see Fig. 6 c. This type of reaction creates none, or only a very small, deformation on the cluster, therefore no significant strain is present.

In reaction 7 and 8 there is no release of hydrogen molecules. Instead the hydrogen atom is transferred to the $\mathrm{SiH}_{2} / \mathrm{SiCl}_{2}$ molecule, creating an adsorbed $\mathrm{SiH}_{3}$ and $\mathrm{SiCl}_{2} \mathrm{H}$ molecule respectively, which chemisorbs at the site were the hydrogen was initially located. Reactions 7 and 8 result in the largest adsorption reaction energy magnitudes per adsorbed molecule. These reactions result in structures where the silicon atom in the adsorbed molecule is situated close to the expected crystal lattice location. There is negligible deformation in the cluster. Also, due to the formation of the additional Si-H bond, the adsorbed silicon atom has no dangling bonds.

To study the influence of cluster size on the reaction energies, reactions 7 and 8 were also modelled on the larger $\mathrm{H}_{72} \mathrm{Si}_{46} \mathrm{C}_{46}$ cluster (Fig. 1k) with the resulting adsorption reaction energies $\Delta \mathrm{E}-211 \mathrm{~kJ} \mathrm{~mol}^{-1}$ and $-116 \mathrm{~kJ}^{-1} 1$, respectively. These values agree favourably with the energies in Table 3 where the smaller cluster $\mathrm{H}_{60} \mathrm{Si}_{33} \mathrm{C}_{33}$ (Fig. 1c) was employed.

At typical SiC CVD temperatures, the surface has been reported to be hydrogen terminated [10]. However, as shown above in section 3.2.1, the formation of hydrogen vacancies in the surface termination is thermodynamically favourable. If the hydrogen termination is not complete, there are a number of free adsorption sites available on the surface and an alternative form of adsorption reaction, similar to reaction 1-6 but without the abstraction of hydrogen, would be possible. These types of reactions will not break any C-H bonds. As a result these reactions will give much stronger adsorption energies compared to reactions 1-6, where two C-H bonds are broken and one $\mathrm{H}-\mathrm{H}$ bond is created, see table 4. 
Table 4. The adsorption reaction energies for $\mathrm{SiH}_{2}$ and $\mathrm{SiCl}_{2}$ reacting with the hydrogen-terminated $\mathrm{SiC}$ surface with one or two $\mathrm{H}$ (surf) vacancies. The Gibbs free energy was calculated using a temperature of $1870 \mathrm{~K}$ and pressures according to table 1 . The functional B3LYP together with the basis set 6-31G(d,p) was used.

\begin{tabular}{|c|c|c|c|}
\hline & \multirow[t]{2}{*}{ Reaction } & \multicolumn{2}{|c|}{ Adsorption reaction energy } \\
\hline & & $\Delta \mathrm{E}\left[\mathrm{kJ} \mathrm{mol}{ }^{-1}\right]$ & $\Delta \mathrm{G}\left[\mathrm{kJ} \mathrm{mol}{ }^{-1}\right]$ \\
\hline 9. & $\mathrm{SiH}_{2}(\mathrm{~g})+\left[\right.$ single $\mathrm{H}($ surf $)$ vacancy] $\rightarrow \mathrm{SiH}_{2}(\mathrm{ads})$ & -255 & 159 \\
\hline 10. & $\mathrm{SiCl}_{2}(\mathrm{~g})+\left[\right.$ single $\mathrm{H}($ surf) vacancy $] \rightarrow \mathrm{SiCl}_{2}$ (ads) & -170 & 265 \\
\hline 11. & $\mathrm{SiH}_{2}(\mathrm{~g})+\left[\right.$ double $\mathrm{H}($ surf $)$ vacancies] $\rightarrow \mathrm{SiH}_{2}($ ads $)$ & -529 & 146 \\
\hline 12. & $2 \mathrm{SiH}_{2}(\mathrm{~g})+[$ double $\mathrm{H}($ surf $)$ vacancies $] \rightarrow 2 \mathrm{SiH}_{2}(\mathrm{ads})$ & -905 & 220 \\
\hline 13. & $\mathrm{SiCl}_{2}(\mathrm{~g})+\left[\right.$ double $\mathrm{H}($ surf) vacancies $] \rightarrow \mathrm{SiCl}_{2}$ (ads) & -426 & 261 \\
\hline 14. & $2 \mathrm{SiCl}_{2}(\mathrm{~g})+[$ double $\mathrm{H}($ surf $)$ vacancies $] \rightarrow 2 \mathrm{SiCl}_{2}(\mathrm{ads})$ & -724 & 448 \\
\hline
\end{tabular}

When considering all reactions 1-8 in table 3 one can see that the $\mathrm{SiH}_{2}$ molecule overall has lower adsorption reaction energy, roughly $100 \mathrm{~kJ} \mathrm{~mol}^{-1}$ per adsorbed molecule lower compared to the $\mathrm{SiCl}_{2}$ molecule, i.e. it is more favourable to adsorb $\mathrm{SiH}_{2}$ than $\mathrm{SiCl}_{2}$. The same results are obtained when letting the two molecules adsorb at vacancy sites, see table 4 .

When studying the Gibbs free energies for all reactions in table 3 and 4 one can notice a large difference from the behaviour of the ordinary adsorption energies. The low concentration of $\mathrm{SiH}_{2}$ and $\mathrm{SiCl}_{2} \mathrm{compared} \mathrm{H}_{2}$ and the low overall pressure in the chamber results in low partial pressures for these two molecules and therefore they are favoured to exist as free particles in the reactions. This leads to a positive value of the adsorption reaction Gibbs free energy, which means that these equilibrium distributions are heavily displaced toward the reactants.

For reaction 7 and 8 (table 3), the transition states between physisorbed and chemisorbed configurations were located and the activation energies for the adsorption were computed, see table 5 . The reaction paths are visualized in Fig. 7. At the transition state, the $\mathrm{Si}$ (molecule)-C(surface) distances are $2.38 \AA$ for $\mathrm{SiH}_{3}$ and $2.39 \AA$ for $\mathrm{SiCl}_{2} \mathrm{H}$. The $\mathrm{H}$ (molecule)-C(surface) distances at the transition state are $1.57 \AA$ for $\mathrm{SiH}_{3}$ and $1.62 \AA$ for $\mathrm{SiCl}_{2} \mathrm{H}$. At the chemisorbed state the corresponding numbers are $1.93,1.90,2.85,2.87 \AA$. 
Table 5. The local-minimum energies for $\mathrm{SiH}_{2}(\mathrm{ads}), \mathrm{SiCl}_{2}(\mathrm{ads})$ and their transition state energies relative the free molecules in $\mathrm{kJ} \mathrm{mol}^{-1}$. The B3LYP functional and the 6-31G(d,p) basis set were used.

\begin{tabular}{lrrr}
\hline Molecule & \multicolumn{2}{c}{$\Delta \mathbf{E}$} \\
& Physisorbed state & Transition state & Chemisorbed state \\
\hline $\mathrm{SiH}_{2}$ & -11 & 77 & -214 \\
$\mathrm{SiCl}_{2}$ & -18 & 216 & -123 \\
\hline
\end{tabular}

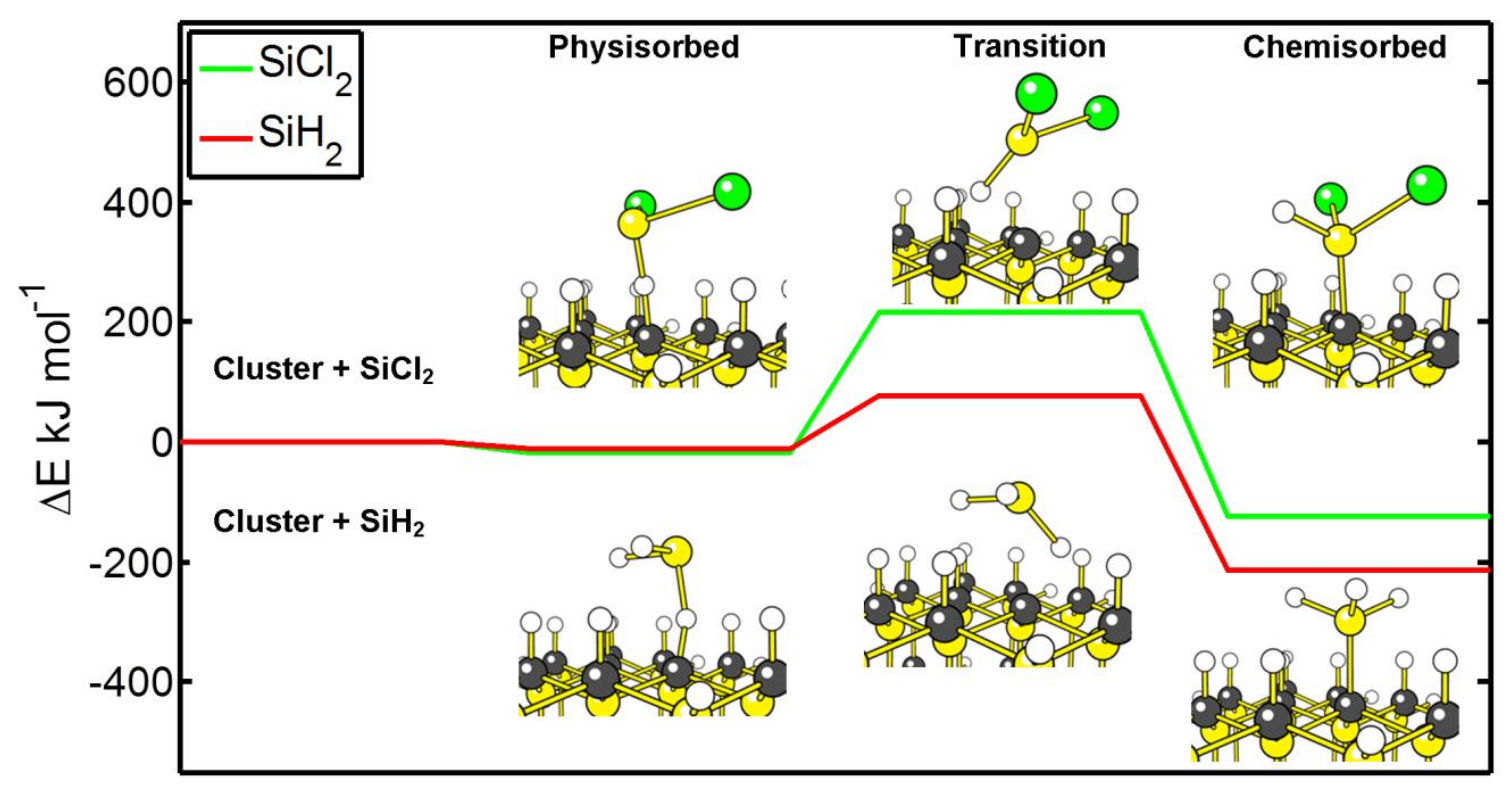

Fig. 7 Reaction paths for the conversion between physisorbed and chemisorbed adsorption states of $\mathrm{SiH}_{2}$ (red) and $\mathrm{SiCl}_{2}$ (green).

As can be seen in Fig. 7 and table 5 the adsorption reaction of $\mathrm{SiH}_{2}$ has a lower activation energy $\left(88 \mathrm{~kJ} \mathrm{~mol}^{-1}\right)$ than the corresponding reaction with $\mathrm{SiCl}_{2}\left(234 \mathrm{~kJ} \mathrm{~mol}^{-1}\right)$ has, implying faster adsorption rates for $\mathrm{SiH}_{2}$ than for $\mathrm{SiCl}_{2}$. One can also notice that the physisorption is stronger for the $\mathrm{SiCl}_{2}$ molecule $\left(7 \mathrm{~kJ} \mathrm{~mol}^{-1}\right.$ stronger), implying a greater tendency to stick to the surface, which is important to initialize the reaction. (It should be noted here that the physisorption energies obtained by B3LYP are uncertain due to the incomplete description of dispersion interactions by this functional. But since the physisorption energies anyhow will be small, this does not influence the discussion significantly.) Further, one can also notice that when the two molecules have been adsorbed (i.e. chemisorbed) it requires larger activation energy to desorb the $\mathrm{SiCl}_{2}$ molecule $\left(339 \mathrm{~kJ} \mathrm{~mol}^{-1}\right)$ 
compared to the $\mathrm{SiH}_{2}$ molecule $\left(291 \mathrm{~kJ} \mathrm{~mol}^{-1}\right)$. The chloride-based CVD chemistry thus seems to provide a more stable surface chemistry during growth, in that once chemisorbed the $\mathrm{SiCl}_{2}$ molecule should have a lower tendency to desorb than the $\mathrm{SiH}_{2}$ molecule.

\subsubsection{Diffusion}

Apart from surface adsorption, surface diffusion is also highly important for a CVD process, especially for epitaxial growth processes. One possible diffusion path on a hydrogen-terminated SiC surface would be the reaction path described in Fig. 7 if both forward and backward directions are combined. An adsorbed molecule would become desorbed by going in the backward reaction path direction. Then the molecule is free to move near the surface to a new position where it readsorbs, which is equivalent to going in the forward reaction path direction. This diffusion path would, using the chemisorption and transition state energies in table 5, have activation energies of $291 \mathrm{~kJ} \mathrm{~mol}^{-1}$ for $\mathrm{SiH}_{2}$ and $339 \mathrm{~kJ} \mathrm{~mol}^{-1}$ for $\mathrm{SiCl}_{2}$. Hence $\mathrm{SiH}_{2}$ should diffuse more easily on the surface according to this reaction path.

Diffusion of $\mathrm{SiH}_{2}$ and $\mathrm{SiCl}_{2}$ on a bare surface was also studied. A diffusion transition state was found for $\mathrm{SiCl}_{2}$ located symmetrically in between the initial and final states seen in Fig. 8, with an activation energy of $107 \mathrm{~kJ}$ $\mathrm{mol}^{-1}$. For the $\mathrm{SiH}_{2}$ molecule this conformation was actually a shallow minimum, with two symmetrically located transition states between the initial/final and shallow minimum structure. The activation energy of $\mathrm{SiH}_{2}$ is $121 \mathrm{~kJ} \mathrm{~mol}^{-1}$ (the energy of the shallow minimum is $118 \mathrm{~kJ} \mathrm{~mol}^{-1}$ ).

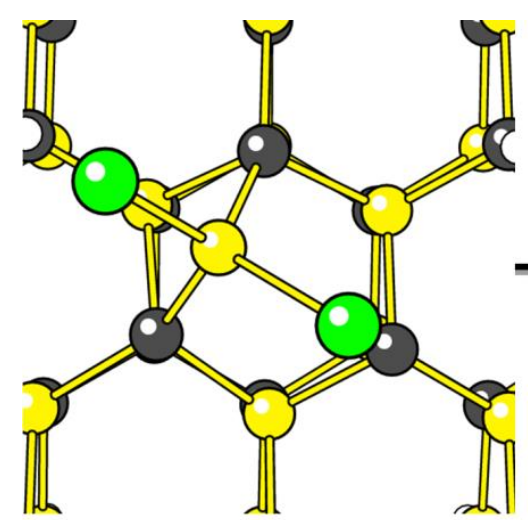

Initial state

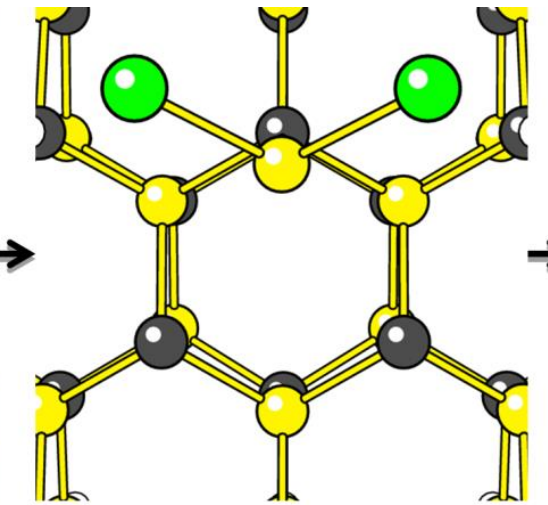

Transition state

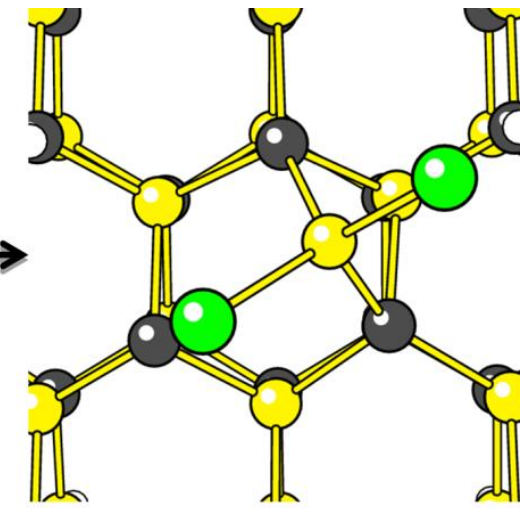

Final state

Fig. 8 Visualization of the reaction path for $\mathrm{SiCl}_{2}$ diffusion. The corresponding path for $\mathrm{SiH}_{2}$ is visually very similar.

The diffusion activation energies for $\mathrm{SiH}_{2}$ and $\mathrm{SiCl}_{2}$ are thus similar with a slightly lower value for $\mathrm{SiCl}_{2}$. These activation energies are considerably smaller compared to the activation energy for diffusion on a hydrogenterminated surface described earlier, 121 compared to $291 \mathrm{~kJ} \mathrm{~mol}^{-1}$ for $\mathrm{SiH}_{2}$, and 107 compared to $339 \mathrm{~kJ} \mathrm{~mol}^{-1}$ 
for $\mathrm{SiCl}_{2}$. Thus in this model, $\mathrm{SiH}_{2}$ and especially $\mathrm{SiCl}_{2}$ diffuse more easily on a bare surface than on a hydrogen-terminated surface.

\section{Conclusions}

Studies of the adsorption of $\mathrm{SiH}_{2}$ and $\mathrm{SiCl}_{2}$ on the $\mathrm{SiC}(000-1)$ surface showed that the $\mathrm{SiH}_{2}$ molecule generally adsorbed roughly $100 \mathrm{~kJ} \mathrm{~mol}^{-1}$ more strongly than the $\mathrm{SiCl}_{2}$ molecule. The activation energy for adsorption of $\mathrm{SiH}_{2}$ on a fully hydrogen-terminated surface was roughly $140 \mathrm{~kJ} \mathrm{~mol}^{-1}$ lower than corresponding activation energy for $\mathrm{SiCl}_{2}$. It should be noted that these activation energies also implies that once adsorbed, the $\mathrm{SiCl}_{2}$ molecule has a lower tendency to desorb than the $\mathrm{SiH}_{2}$ molecule. Another observation was that the $\mathrm{SiCl}_{2}$ molecule physisorbed somewhat stronger than the $\mathrm{SiH}_{2}$ molecule on the hydrogen terminated surface. This might be an important property to initialize the adsorption reaction.

For surface diffusion of $\mathrm{SiH}_{2}$ and $\mathrm{SiCl}_{2}$ on the fully hydrogen-terminated $\mathrm{SiC}$ surface, the activation energy for $\mathrm{SiH}_{2}$ was $50 \mathrm{~kJ} \mathrm{~mol}^{-1}$ lower compared to that for the $\mathrm{SiCl}_{2}$ molecule. On a $\mathrm{SiC}$ surface without hydrogen termination, these activation energies were significantly lower: 121 compared to $291 \mathrm{~kJ} \mathrm{~mol}^{-1}$ for $\mathrm{SiH}_{2}$ and 107 $\mathrm{kJ} \mathrm{mol}^{-1}$ compared to $339 \mathrm{~kJ} \mathrm{~mol}^{-1}$ for $\mathrm{SiCl}_{2}$. On the bare surface the $\mathrm{SiCl}_{2}$ molecule has the lowest activation energy by $14 \mathrm{~kJ} \mathrm{~mol}^{-1}$. Thus $\mathrm{SiH}_{2}$ will diffuse more easily compared to $\mathrm{SiCl}_{2}$ on a fully hydrogen terminated surface. Both molecules will diffuse more easily on a bare surface and here the $\mathrm{SiCl}_{2}$ molecule diffuses slightly more easily than the $\mathrm{SiH}_{2}$ molecule.

Since the silicon growth specie in a chloride-based $\mathrm{SiC} \mathrm{CVD} \mathrm{process,} \mathrm{SiCl}_{2}$, once chemisorbed has a lower tendency to desorb than $\mathrm{SiH}_{2}$, this implies that with a chlorinated chemistry the chemisorbed $\mathrm{Si}$ atoms are more likely to build up the SiC epitaxial layer. Thus, these results suggest that chlorinated chemistry constitutes a good choice for CVD growth of SiC epitaxial layers.

Acknowledgements.

The Swedish Research Council VR, the Swedish Foundation for Strategic Research SSF and the Swedish National Supercomputer Centre NSC, are gratefully acknowledged. 


\section{References}

[1] Chelnokov VE, Syrkin AL (1997) Materials Science and Engineering B46:248-253

[2] Lebedev AA, Chelnokov VE (1999) Semiconductors 33:999-1001

[3] Kimoto T, Itoh A, Matsunami H (1997) Phys Status Solidi B 202:247-262

[4] Crippa D, Rode DL, Masi M (2001) Semiconductors and Semimetals 72:1-491

[5] Aylward G, Findlay T (1998) SI Chemical Data 4th ed. John Wiley \& Sons, Australia (p 115)

[6] Pedersen H, Leone S, Kordina O, Henry A, Nishizawa S, Koshka Y, Janzén E (2012) Chem Rev 112:24342453

[7] Valente G, Cavallotti C, Masi M, Carrà C (2001) J Cryst Growth 230:247-257

[8] Nigam S, Chung HJ, Polyakov AY, Fanton MA, Weiland BE, Snyder DW, Skowronski M (2005) J Cryst Growth 284:112-122

[9] Veneroni A, Omarini F, Masi M (2005) Cryst Res Technol 40:967-971

[10] Olander J, Larsson K (2004) Thin Solid Films 458:191-196

[11] Olander J, Larsson K (2001) J Phys Chem B 105:7619-7623

[12] Wachowicz E, Kiejna A (2012) J Phys Condens Matter 24:385801(7pp)

[13] Ellison A (1999) Silicon Carbide Growth by High Temperature CVD Techniques, Diss Thesis no 599, Linköping University, Linköping, Sweden

[14] Schlegel HB (1982) J Comp Chem 3:214-218

[15] Becke AD (1993) J Chem Phys 98:5648-5652.

[16] Lee C, Yang W, Parr RG (1988) Phys Rev B 37:785-789.

[17] Bouteiller Y, Mijoule C, Nizam M, Barthelat JC, Daudey JP, Pelissier M, Silvi B (1988) Mol Phys 65:295312

[18] Durand P, Barthelat JC (1975) Theor Chim Acta 38:283-302

[19] Hehre WJ, Ditchfield R, Pople JA (1972) J Chem Phys 56:2257-2261

[20] Head-Gordon M, Pople JA, Frisch MJ (1988) Chem Phys Lett 153:503-506

[21] Pople JA, Head-Gordon M, Raghavachari K (1987) J Chem Phys 87:5968-5975

[22] Frisch MJ, Pople JA, Binkley JS (1984) J Chem Phys 80:3265-3269

[23] Frisch MJ, Trucks GW, Schlegel HB, Scuseria GE, Robb MA, Cheeseman JR, Scalmani G, Barone V, Mennucci B, Petersson GA, Nakatsuji H, Caricato M, Li X, Hratchian HP, Izmaylov AF, Bloino J, Zheng G, Sonnenberg JL, Hada M, Ehara M, Toyota K, Fukuda R, Hasegawa J, Ishida M, Nakajima T, Honda Y, Kitao O, Nakai H, Vreven T, Montgomery JrJA, Peralta JE, Ogliaro F, Bearpark M, Heyd JJ, Brothers E, Kudin KN, Staroverov VN, Kobayashi R, Normand J, Raghavachari K, Rendell A, Burant JC, Iyengar SS, Tomasi J, Cossi M, Rega N, Millam JM, Klene M, Knox JE, Cross JB, Bakken V, Adamo C, Jaramillo J, Gomperts R, Stratmann RE, Yazyev O, Austin AJ, Cammi R, Pomelli C, Ochterski JW, Martin RL, Morokuma K, Zakrzewski VG, Voth 
GA, Salvador P, Dannenberg JJ, Dapprich S, Daniels AD, Farkas Ö, Foresman JB, Ortiz JV, Cioslowski J, Fox DJ Gaussian IncWallingford CT 2009

[24] Peng C, Ayala PY, Schlegel HB, Frisch MJ (1996) J Comp Chem 17:49-56

[25] Peng C, Schlegel HB (1993) Israel J Chem 33:449-54

[26] Halgren TA, Lipscomb WN (1977) Chem Phys Lett 49:225-232

[27] Coffin JM, Hamilton TP, Pulay P, Hargittai I (1989) Inorg Chem 28:4092-4094

[28] Hermansson K, Ojamäe L, "MOVIEMOL: an easy-to-use molecular display and animation program User Manual," Report No UUIC-B19-500, Institute of Chemistry, Uppsala University (1994)

[29] Brena B, Ojamäe L (2008) J Phys Chem C 112:13516-13523

[30] Trwoga PF, Kenyon AJ, Pitt CW (1998) J Appl Phys 83:3789-3794

[31] Choyke WJ, Hamiltgn DR, Patrick L (1964) Phys Rev 133:A1163-A1166 